\title{
Metabolic syndrome in patients with type 2 diabetes and atherosclerotic cardiovascular disease: a post hoc analyses of the EMPA-REG OUTCOME trial
}

João Pedro Ferreira ${ }^{1 *} \oplus$, Subodh Verma², David Fitchett ${ }^{3}$, Anne Pernille Ofstad ${ }^{4}$, Sabine Lauer ${ }^{5}$, Isabella Zwiener ${ }^{5}$, Jyothis George ${ }^{6}$, Christoph Wanner ${ }^{7}$, Bernard Zinman ${ }^{8}$ and Silvio E. Inzucchi ${ }^{9}$

\begin{abstract}
Background: Patients with type 2 diabetes (T2D) and metabolic syndrome (MetS) are at greater cardiovascular risk than those with T2D without MetS. In the current report we aim to study the characteristics, cardio-renal outcomes and the effect of empagliflozin in patients with MetS enrolled in the EMPA-REG OUTCOME trial.

Methods: A total of 7020 patients with T2D and atherosclerotic cardiovascular disease were treated with empagliflozin $(10 \mathrm{mg}$ or $25 \mathrm{mg}$ ) or placebo for a median of 3.1 years. The World Health Organization MetS criteria could be determined for 6985 (99.5\%) patients. We assessed the association between baseline MetS and multiple cardio-renal endpoints using Cox regression models, and we studied the change in the individual component over time of the MetS using mixed effect models.

Results: MetS at baseline was present in 5740 (82\%) patients; these were more often white and had more often albuminuria and heart failure, had lower eGFR and HDL-cholesterol, and higher blood pressure, body mass index, waist circumference, and triglycerides. In the placebo group, patients with MetS had a higher risk of all outcomes including cardiovascular death: $\mathrm{HR}=1.73$ (95\% Cl 1.01-2.98), heart failure hospitalization: $\mathrm{HR}=2.64$ (95\% Cl 1.22, 5.72), and new or worsening nephropathy: $\mathrm{HR}=3.11$ (95\% Cl2.17-4.46). The beneficial effect of empagliflozin was consistent on all cardio-renal outcomes regardless of presence of MetS.
\end{abstract}

Conclusions: A large proportion of the EMPA-REG OUTCOME population fulfills the criteria for MetS. Those with MetS had increased risk of adverse cardio-renal outcomes. Compared with placebo, empagliflozin improved cardio-renal outcomes in patients with and without MetS.

Trial registration Clinical Trial Registration: URL: https://www.clinicaltrials.gov. Unique identifier: NCT 01131676

Keywords: Type 2 diabetes mellitus, Metabolic syndrome, Empagliflozin, Treatment effect, Cardiovascular disease

\footnotetext{
*Correspondence: j.ferreira@chru-nancy.fr

${ }^{1}$ Centre d'Investigations Cliniques Plurithématique Inserm 1433, CHRU

de Nancy, Inserm U1116, FCRIN INI- CRCT, Université de Lorraine, Nancy, France

Full list of author information is available at the end of the article
}

\section{Introduction}

Metabolic syndrome (MetS) comprises interrelated risk factors that, together, contribute to a cumulative risk of cardiovascular (CV) complications [1]. The World Health Organization (WHO) defines MetS by the presence of insulin resistance [e.g. type 2 diabetes (T2D) or indications of abnormal glucose metabolism], together with at

(c) The Author(s) 2020. This article is licensed under a Creative Commons Attribution 4.0 International License, which permits use, sharing, adaptation, distribution and reproduction in any medium or format, as long as you give appropriate credit to the original author(s) and the source, provide a link to the Creative Commons licence, and indicate if changes were made. The images or other third party material in this article are included in the article's Creative Commons licence, unless indicated otherwise in a credit line to the material. If material is not included in the article's Creative Commons licence and your intended use is not permitted by statutory regulation or exceeds the permitted use, you will need to obtain permission directly from the copyright holder. To view a copy of this licence, visit http://creativeco mmons.org/licenses/by/4.0/. The Creative Commons Public Domain Dedication waiver (http://creativecommons.org/publicdomain/ zero/1.0/) applies to the data made available in this article, unless otherwise stated in a credit line to the data. 
Table 1 Baseline characteristics in the treatment groups separately in patients with versus those without metabolic syndrome at baseline

\begin{tabular}{|c|c|c|c|c|}
\hline & \multicolumn{2}{|c|}{ With metabolic syndrome } & \multicolumn{2}{|c|}{ Without metabolic syndrome } \\
\hline & $\begin{array}{l}\text { Placebo } \\
n=1902\end{array}$ & $\begin{array}{l}\text { Empagliflozin } \\
n=3838\end{array}$ & $\begin{array}{l}\text { Placebo } \\
n=426\end{array}$ & $\begin{array}{l}\text { Empagliflozin } \\
\mathrm{n}=819\end{array}$ \\
\hline Female & $546(28.7)$ & $1119(29.2)$ & $104(24.4)$ & $228(27.8)$ \\
\hline \multicolumn{5}{|l|}{ Ethnicity } \\
\hline White & $1423(74.8)$ & $2891(75.3)$ & $251(58.9)$ & $491(60.0)$ \\
\hline Black/African American & $101(5.3)$ & $187(4.9)$ & $19(4.5)$ & $48(5.9)$ \\
\hline Asian & $359(18.9)$ & $723(18.8)$ & $151(35.4)$ & $276(33.7)$ \\
\hline Native Hawaiian & $3(0.2)$ & $5(0.1)$ & $1(0.2)$ & $1(0.1)$ \\
\hline American Indian, Alaskan & $16(0.8)$ & $31(0.8)$ & $4(0.9)$ & $3(0.4)$ \\
\hline Missing & 0 & $1(<0.1)$ & 0 & 0 \\
\hline Age, years & $63.1 \pm 8.7$ & $63.1 \pm 8.5$ & $63.7 \pm 9.1$ & $63.2 \pm 8.9$ \\
\hline \multicolumn{5}{|l|}{ T2D duration, years } \\
\hline$\leq 1$ & $46(2.4)$ & $106(2.8)$ & $6(1.4)$ & $21(2.6)$ \\
\hline$>1$ to 5 & $309(16.2)$ & $579(15.1)$ & $61(14.3)$ & $126(15.4)$ \\
\hline$>5$ to 10 & $474(24.9)$ & $986(25.7)$ & $95(22.3)$ & $186(22.7)$ \\
\hline$>10$ & $1073(56.4)$ & $2167(56.5)$ & $264(62.0)$ & $486(59.3)$ \\
\hline \multicolumn{5}{|l|}{ Medication } \\
\hline Metformin ${ }^{a}$ & $1415(74.4)$ & $2840(74.0)$ & $315(73.9)$ & $599(73.1)$ \\
\hline Insulin & $967(50.8)$ & $1912(49.8)$ & $166(39.0)$ & $324(39.6)$ \\
\hline Beta blocker & $1268(66.7)$ & $2579(67.2)$ & $227(53.3)$ & $459(56.0)$ \\
\hline Diuretics & $871(45.8)$ & $1785(46.5)$ & $116(27.2)$ & $254(31.0)$ \\
\hline ACEi/ARBs & $1571(82.6)$ & $3200(83.4)$ & $293(68.8)$ & $576(70.3)$ \\
\hline Statins & $1431(75.2)$ & $2959(77.1)$ & $338(79.3)$ & $646(78.9)$ \\
\hline $\mathrm{eGFR}, \mathrm{mL} / \mathrm{min} / 1.73 \mathrm{~m}^{2}$ & $72.83 \pm 21.25$ & $73.12 \pm 21.83$ & $78.25 \pm 19.66$ & $78.91 \pm 19.88$ \\
\hline Prior stroke & $448(23.6)$ & $923(24.0)$ & $104(24.4)$ & $155(18.9)$ \\
\hline Prior CAD & $1444(75.9)$ & $2901(75.6)$ & $315(73.9)$ & $619(75.6)$ \\
\hline Prior MI & $895(47.1)$ & $1799(46.9)$ & $186(43.7)$ & $382(46.6)$ \\
\hline Prior PAD & $387(20.3)$ & $813(21.2)$ & $90(21.1)$ & $164(20.0)$ \\
\hline Heart failure & $219(11.5)$ & $399(10.4)$ & $25(5.9)$ & $61(7.4)$ \\
\hline Retinopathy & $429(22.6)$ & $856(22.3)$ & $93(21.8)$ & $164(20.0)$ \\
\hline $\mathrm{BMI}, \mathrm{kg} / \mathrm{m}^{2}$ & $31.65 \pm 5.17$ & $31.57 \pm 5.19$ & $26.28 \pm 2.71$ & $26.22 \pm 2.83$ \\
\hline Weight, kg & $89.46 \pm 19.13$ & $89.15 \pm 18.83$ & $74.15 \pm 12.53$ & $72.78 \pm 12.30$ \\
\hline Waist circumference, cm & $107.2 \pm 13.8$ & $107.0 \pm 13.4$ & $95.2 \pm 9.6$ & $94.2 \pm 9.5$ \\
\hline $\mathrm{SBP}, \mathrm{mmHg}$ & $136.8 \pm 17.4$ & $136.4 \pm 17.1$ & $131.4 \pm 16.0$ & $130.0 \pm 15.4$ \\
\hline $\mathrm{DBP}, \mathrm{mmHg}$ & $77.3 \pm 10.3$ & $77.2 \pm 9.8$ & $74.8 \pm 9.3$ & $73.9 \pm 9.0$ \\
\hline $\mathrm{HbA} 1 \mathrm{c}, \%$ & $8.10 \pm 0.85$ & $8.10 \pm 0.85$ & $7.97 \pm 0.80$ & $7.94 \pm 0.81$ \\
\hline \multicolumn{5}{|l|}{ UACR } \\
\hline Normal (<30 mg/g) & $971(51.1)$ & $1968(51.3)$ & $407(95.5)$ & $803(98.0)$ \\
\hline Micro (30-300 mg/g) & $663(34.9)$ & $1325(34.5)$ & $12(2.8)$ & $12(1.5)$ \\
\hline Macro (> 300 mg/g) & $254(13.4)$ & $505(13.2)$ & $6(1.4)$ & $4(0.5)$ \\
\hline Missing & $14(0.7)$ & $40(1.0)$ & $1(0.2)$ & 0 \\
\hline Uric acid, mg/dL & $6.11 \pm 1.68$ & $6.05 \pm 1.67$ & $5.51 \pm 1.50$ & $5.48 \pm 1.41$ \\
\hline ASAT, U/L & $23.07 \pm 10.65$ & $22.61 \pm 9.81$ & $22.05 \pm 8.75$ & $21.93 \pm 8.69$ \\
\hline ALAT, U/L & $26.74 \pm 15.85$ & $25.88 \pm 14.01$ & $24.13 \pm 12.25$ & $23.77 \pm 12.47$ \\
\hline $\mathrm{HDL}-\mathrm{C}, \mathrm{mg} / \mathrm{dL}$ & $42.6 \pm 10.8$ & $43.3 \pm 11.6$ & $50.6 \pm 11.3$ & $50.5 \pm 11.2$ \\
\hline LDL-C, mg/dL & $85.6 \pm 36.0$ & $86.4 \pm 36.6$ & $81.6 \pm 32.3$ & $83.6 \pm 32.4$ \\
\hline Triglycerides, mg/dL & $185.8 \pm 128.4$ & $185.1 \pm 138.1$ & $103.6 \pm 35.6$ & $103.6 \pm 31.2$ \\
\hline Fufilling 2 criteria $^{b}$ & $730(38.4)$ & $1500(39.1)$ & NA & NA \\
\hline
\end{tabular}


Table 1 (continued)

\begin{tabular}{|c|c|c|c|c|}
\hline & \multicolumn{2}{|c|}{ With metabolic syndrome } & \multicolumn{2}{|c|}{ Without metabolic syndrome } \\
\hline & $\begin{array}{l}\text { Placebo } \\
n=1902\end{array}$ & $\begin{array}{l}\text { Empagliflozin } \\
\mathrm{n}=3838\end{array}$ & $\begin{array}{l}\text { Placebo } \\
n=426\end{array}$ & $\begin{array}{l}\text { Empagliflozin } \\
\mathrm{n}=\mathbf{8 1 9}\end{array}$ \\
\hline Fulfilling 3 criteriab $^{b}$ & $661(34.8)$ & $1332(34.7)$ & NA & NA \\
\hline Fufilling 4 or 5 criteriab $^{b}$ & $478(25.1)$ & $936(24.4)$ & NA & NA \\
\hline $\begin{array}{l}\text { Not evaluable for number of fulfilled } \\
\text { criteriac }^{c}\end{array}$ & $33(1.7)$ & $77(2.0)$ & NA & NA \\
\hline
\end{tabular}

Data are $\mathrm{n}(\%)$ or mean $\pm \mathrm{SD}$

$A C E i$ angiotensin converting enzyme inhibitor, $A R B$ angiotensin receptor blocker, $A L A T$ aspartate amino transferase, $A S A T$ aspartate amino transferase, $B M I$ body mass index, $C A D$ coronary artery disease, $D B P$ diastolic blood pressure, eGFR estimated glomerular filtration rate, $H b A 1 C$ glycated hemoglobin, $H D L-C$ high-density lipoprotein cholesterol, $L D L-C$ low-density lipoprotein cholesterol, $M I$ myocardial infarction, $P A D$ peripheral artery disease, $S B P$ systolic blood pressure, $T 2 D$ type 2 diabetes, UACR urine albumin-creatinine ratio

a Background medication at baseline

b Of the additional WHO diagnostic criteria on top of insulin resistance/diabetes

c Patients with MetS and 2 or 3 criteria fulfilled but not evaluable for at least one of the remaining criteria

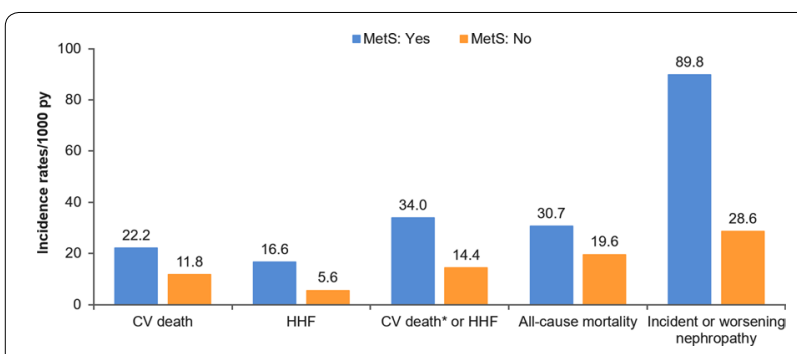

Fig. 1 Incidence rates of outcomes in the placebo group in those with versus those without metabolic syndrome at baseline. *Excluding fatal stroke. CV cardiovascular, HHF hospitalization for HF, PY patient years

least two of the following factors: use of anti-hypertensive medication and/or high blood pressure (BP) $\geq 140 \mathrm{mmHg}$ systolic or $\geq 90 \mathrm{mmHg}$ diastolic], plasma triglycerides $>150 \mathrm{mg} / \mathrm{dL}, \mathrm{HDL}$ cholesterol $<35 \mathrm{mg} / \mathrm{dL}$ in men or $<39 \mathrm{mg} / \mathrm{dL}$ in women, body mass index $(\mathrm{BMI})>30 \mathrm{~kg} / \mathrm{m}^{2}$ and/or waist-hip ratio $>0.9$ in men, $>0.85$ in women, and urinary albumin excretion rate $\geq 20 \mu \mathrm{g} / \mathrm{min}$ or albumincreatinine ratio (UACR) $\geq 3.4 \mathrm{mg} / \mathrm{mmol}$ [2]. A recent report demonstrated that even among patients with diabetes, those with uncontrolled components of the MetS, are at higher risk for adverse CV outcomes [3]. Therefore, improving any or several of the factors defining MetS may improve $\mathrm{CV}$ outcomes in patients with diabetes.

In the EMPA-REG OUTCOME trial [4], the SGLT2 inhibitor empagliflozin reduced the risk of $\mathrm{CV}$ death, hospitalization for heart failure (HF) and incident or worsening nephropathy compared with placebo in patients with $\mathrm{T} 2 \mathrm{D}$ and atherosclerotic $\mathrm{CV}$ disease (ASCVD). Empagliflozin also reduced HbA1c, BP, body weight and UACR [5-8]. To extend these findings, we sought to explore whether the MetS confers higher risk of events in patients with diabetes and ASCVD, if empagliflozin can positively impact the individual components of the MetS, and whether the cardiorenal benefits of empagliflozin extended equally to those with vs. without MetS.

\begin{tabular}{|c|c|c|c|c|c|c|c|}
\hline \multirow[b]{3}{*}{$\mathrm{CV}$ death } & \multicolumn{2}{|c|}{ Mets: Yes } & \multicolumn{2}{|c|}{ Mets: No } & \multirow{2}{*}{\multicolumn{2}{|c|}{ HR $(95 \% \mathrm{Cl})$}} & \multirow{2}{*}{$\begin{array}{l}p \text {-value for } \\
\text { interaction }\end{array}$} \\
\hline & $n / N$ & $\%$ & $\mathrm{n} / \mathrm{N}$ & $\%$ & & & \\
\hline & $122 / 1902$ & 6.4 & $15 / 426$ & 3.5 & $1.73(1.01,2.98)$ & $\longrightarrow$ & 0.0464 \\
\hline HHF & $88 / 1902$ & 4.6 & $7 / 426$ & 1.6 & $2.64(1.22,5.72)$ & $\longrightarrow$ & 0.0140 \\
\hline $\mathrm{CV}$ death* or HHF & $180 / 1902$ & 9.5 & $18 / 426$ & 4.2 & $2.12(1.30,3.46)$ & $\longmapsto$ & 0.0025 \\
\hline All-cause mortality & $169 / 1902$ & 8.9 & $25 / 426$ & 5.9 & $1.49(0.97,2.27)$ & $\longrightarrow$ & 0.0668 \\
\hline \multirow[t]{3}{*}{ Incident or worsening nephropathy } & $354 / 1641$ & 21.6 & $33 / 415$ & 8.0 & $3.11(2.17,4.06)$ & $\longmapsto$ & $<0.0001$ \\
\hline & & & & & 0.5 & 4 & 8 \\
\hline & & & \multicolumn{5}{|c|}{$\begin{array}{c}\text { Decreased risk Increased risk } \\
\text { For patients with MetS }\end{array}$} \\
\hline \multicolumn{8}{|c|}{$\begin{array}{l}\text { Fig. } 2 \text { Association of metabolic syndrome at baseline and outcomes in the placebo group(patients without metabolic syndrome is reference } \\
\text { group). }{ }^{*} \text { Excluding fatal stroke. Cox models include terms for baseline age, sex, HbA1C, eGFR, geographical region, treatment, MetS at baseline and } \\
\text { treatment*MetS at baseline interaction. CV cardiovascular, HHF hospitalization for heart failure, MetS metabolic syndrome }\end{array}$} \\
\hline
\end{tabular}




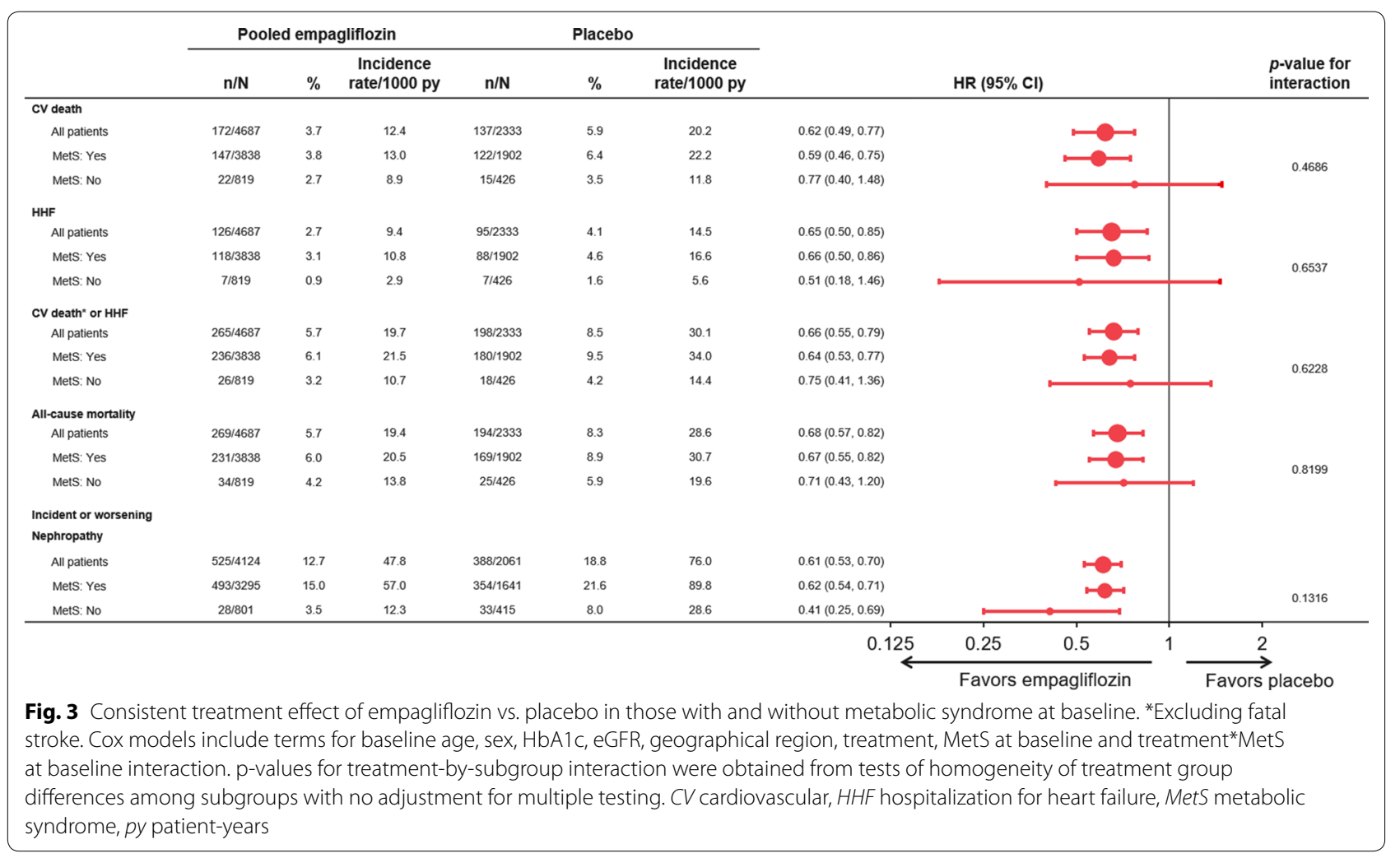

\section{Materials and methods \\ Study design}

The design of EMPA-REG OUTCOME has been described previously [4]. Briefly, the study population comprised patients with type 2 diabetes, established ASCVD, HbA1c 7.0-9.0\% for drug-naïve patients and $7.0-10.0 \%$ for those on stable glucose-lowering therapy, and an estimated glomerular filtration rate (eGFR) [determined by the Modification of Diet in Renal Disease (MDRD) equation] $\geq 30 \mathrm{~mL} / \mathrm{min} / 1.73 \mathrm{~m}^{2}$. Patients were randomized $1: 1: 1$ to receive empagliflozin $10 \mathrm{mg}$, empagliflozin $25 \mathrm{mg}$, or placebo in addition to standard of care. The first 12 weeks, blood glucose lowering treatment was to be kept unchanged. Thereafter and throughout the trial, investigators were encouraged to adjust diabetes medication and treat cardiovascular risk factors to achieve optimal standard of care according to local guidelines. The trial was to continue until $\geq 691$ patients had experienced an adjudicated event included in the primary outcome [3-point major adverse CV events (3P-MACE): CV death, non-fatal myocardial infarction (MI), or non-fatal stroke].

\section{Outcomes}

In the current analyses we explore $\mathrm{CV}$ death, hospitalization for $\mathrm{HF}, \mathrm{CV}$ death or hospitalization for $\mathrm{HF}$ (excluding fatal stroke), all-cause mortality, 3P-MACE, and incident or worsening nephropathy defined as progression to macroalbuminuria, doubling of the serum creatinine level accompanied by an eGFR of $\leq 45 \mathrm{ml}$ per minute per $1.73 \mathrm{~m} 2$, initiation of continuous renalreplacement therapy, or death from renal disease $[4,8]$. All cardiovascular outcome events and deaths were prospectively adjudicated by two clinical events committees (for cardiac and neurological events).

\section{Definition of metabolic syndrome}

We used the WHO definition of MetS (2) where the first criteria (insulin resistance or diabetes) was present in all patients. Urinary albumin excretion rate and waist/hipratio were not assessed in the trial. Hence, at least two criteria of the following needed to be fulfilled to qualify a patient as having MetS: (1) use of antihypertensive medication and/or high BP $(\geq 140 \mathrm{mmHg}$ systolic or $\geq 90 \mathrm{mmHg}$ diastolic), (2) plasma triglycerides $>150 \mathrm{mg} /$ $\mathrm{dL}(\geq 1.7 \mathrm{mmol} / \mathrm{L})$, (3) HDL cholesterol $<35 \mathrm{mg} / \mathrm{dL}$ $(<0.9 \mathrm{mmol} / \mathrm{L})$ in men or $<39 \mathrm{mg} / \mathrm{dL}(<1.0 \mathrm{mmol} / \mathrm{L})$ in women, (4) $\mathrm{BMI}>30 \mathrm{~kg} / \mathrm{m}^{2}$, and (5) UACR $\geq 3.4 \mathrm{mg} /$ mmol. In the current analyses, we applied the cut-offs as given in $\mathrm{mmol} / \mathrm{L}$. Hence, this post-hoc analysis includes patients with T2D and if two additional features of the MetS are present these patients are classified as having 
T2D and MetS, referred to as "with MetS" throughout the manuscript and tables.

\section{Statistical analyses}

All analyses were undertaken in patients that were treated with at least one dose of study drug and had baseline information for assessment of MetS available. Descriptive data are given as mean \pm standard deviation, or proportions (\%). We split the population into two subgroups (with vs. without MetS at baseline) based on whether the criteria for MetS were fulfilled or not. Incidence rates per 1000 patient years of follow-up were calculated in the placebo group. The association of subgroup to outcomes and the treatment effect of pooled empagliflozin vs. placebo was explored by Cox proportional hazards models with terms for age, sex, geographic region, baseline HbA1c, baseline eGFR, treatment, subgroup and subgroup*treatment interaction. In addition, we assessed if there was any treatment interaction with subgroups based on how many of the diagnostic criteria for MetS that were fulfilled among those with MetS at baseline using the same Cox model. Treatment effects on the separate components of MetS [HbA1c, systolic $\mathrm{BP}$, weight, waist circumference (WC), HDL-cholesterol, triglycerides, and UACR] were evaluated using mixed effect model repeat measurement (MMRM) models. The models included subject as a random effect, and baseline HbA1c plus the baseline value of the MetS component being explored as linear covariates along with their interaction with visit time (weeks). Additionally, baseline eGFR, baseline BMI and geographic region were also used as adjustment covariates in the models. The MMRM model also included a fixed categorical effect for 'time of randomization' to account for each patient's theoretical ability to 'reach' certain weeks in this study arising from the study design. In addition, the model included the terms visit, treatment and MetS at baseline, as well as all two-and three-way interactions thereof. For UACR, values were assumed to be not normally distributed, such that values were $\log$-transformed prior to analyses. All analyses were performed with SAS version 9.4.

\section{Results}

\section{Baseline characteristics}

Of the 7020 patients randomized and treated in the trial, 6985 (99.5\%) had baseline information available to evaluate the MetS criteria. Of these, $5740(82 \%)$ had MetS $(1902 / 3838$ in placebo/empagliflozin groups, respectively). Baseline characteristics comparing patients with and without MetS are shown in Table 1. As expected, those with MetS were more often white and had more often albuminuria, had lower eGFR and HDL-cholesterol, and higher blood pressure, $\mathrm{BMI}, \mathrm{WC}$, and triglycerides. Furthermore, they used more BP lowering drugs, and had a HF diagnosis more often than those without MetS.

\section{Cardiorenal, mortality and HF outcomes}

Patients with MetS had increased risk of all outcomes with incidence rates in the placebo group of approximately 1.5 to 3 -fold higher than the rates observed in patients without MetS in the placebo group (Fig. 1). The increase in risk was highest for incident or worsening nephropathy with a hazard ratio (HR) of $3.11(2.17,4.46)$, $\mathrm{p}<0.0001$ (Fig. 2). Empagliflozin reduced the risk of all of these outcomes and was consistent in those patients with MetS and without MetS (all interaction p-values $>0.05$ ) (Fig. 3). Additionally, the treatment effect was furthermore consistent in patients with MetS regardless of whether they fulfilled 2, 3 or of the additional diagnostic criteria for MetS (interaction p-value for CV death: $=0.24$, hospitalization for $\mathrm{HF}=0.65, \mathrm{CV}$ death or hospitalization for HF 0.40, all-cause mortality 0.24). For new or worsening nephropathy there was a nominally significant quantitative interaction with a p-value of 0.0013 due to an inconsistent pattern of treatment effect (U-shaped pattern with lowest HRs of 0.45 and 0.42 in patients without MetS and those fulfilling 4-5 criteria compared to HRs of 0.81 and 0.71 in those fulfilling 2 or 3 criteria, respectively).

\section{Effects on metabolic outcomes}

Empagliflozin reduced HbA1c, SBP, weight, and WC similarly in those with and without metabolic syndrome (Fig. 4). There was a small increase in HDL-C with empagliflozin in both those with or without MetS, whereas triglycerides were not clinically relevantly changed by empagliflozin. UACR was reduced in patients with MetS, whereas in those without MetS, UACR hardly changed over time in any treatment group.

\section{Discussion}

The current analyses show that the majority of the patients included in the EMPA-REG OUTCOME trial fulfilled the WHO criteria for MetS. This is not surprising since MetS is a risk factor for T2D as well as CV disease, both of which constituted inclusion criteria for the trial. Those participants with MetS in fact were at higher risk of adverse CV outcomes. Nonetheless, empagliflozin reduced $\mathrm{CV}$ and $\mathrm{HF}$ events as well as new or worsening nephropathy irrespective of the MetS status. Importantly, empagliflozin reduced many components of the MetS over time, including WC, SBP, weight, and UACR (only triglycerides were not reduced). Each of these may be 


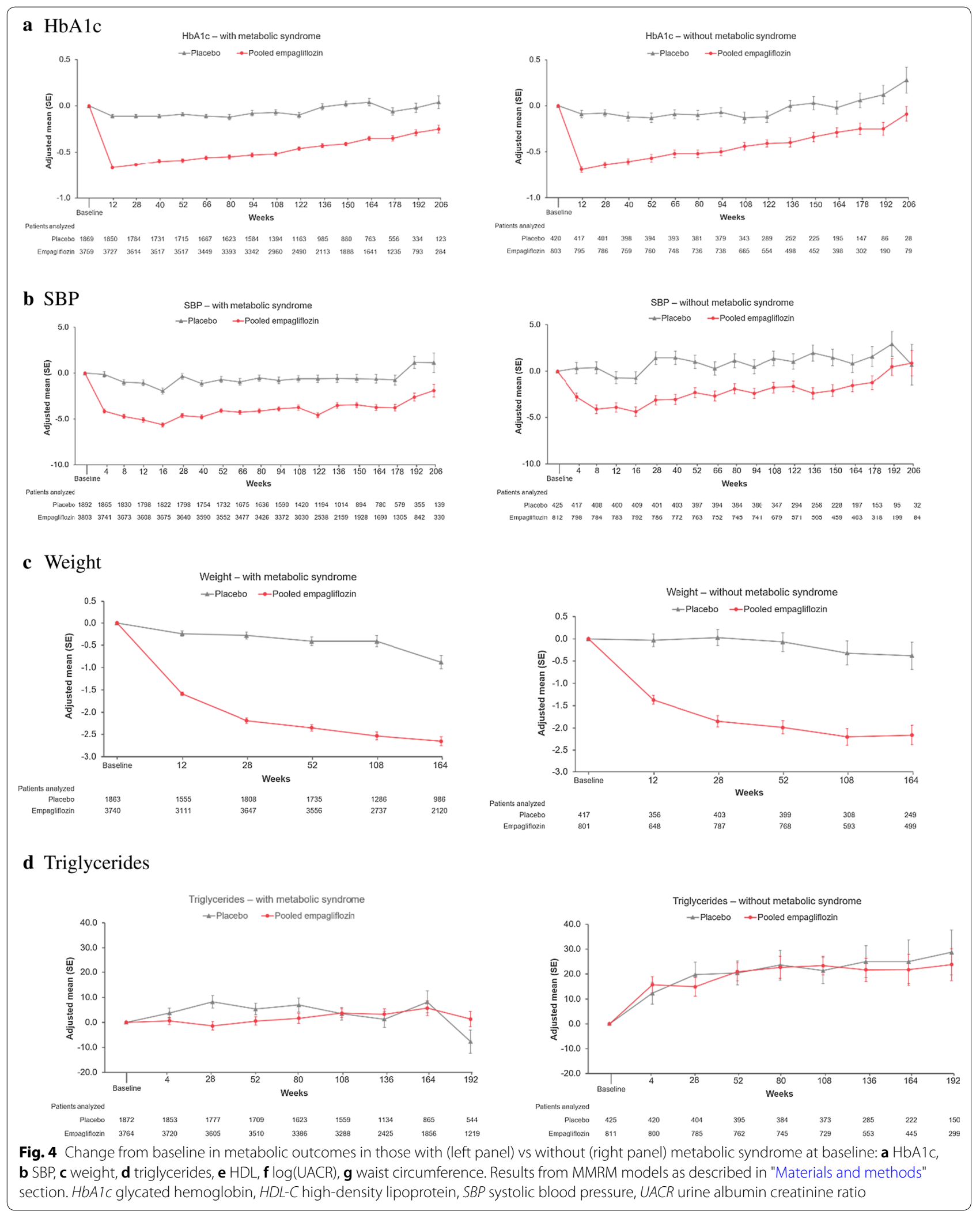




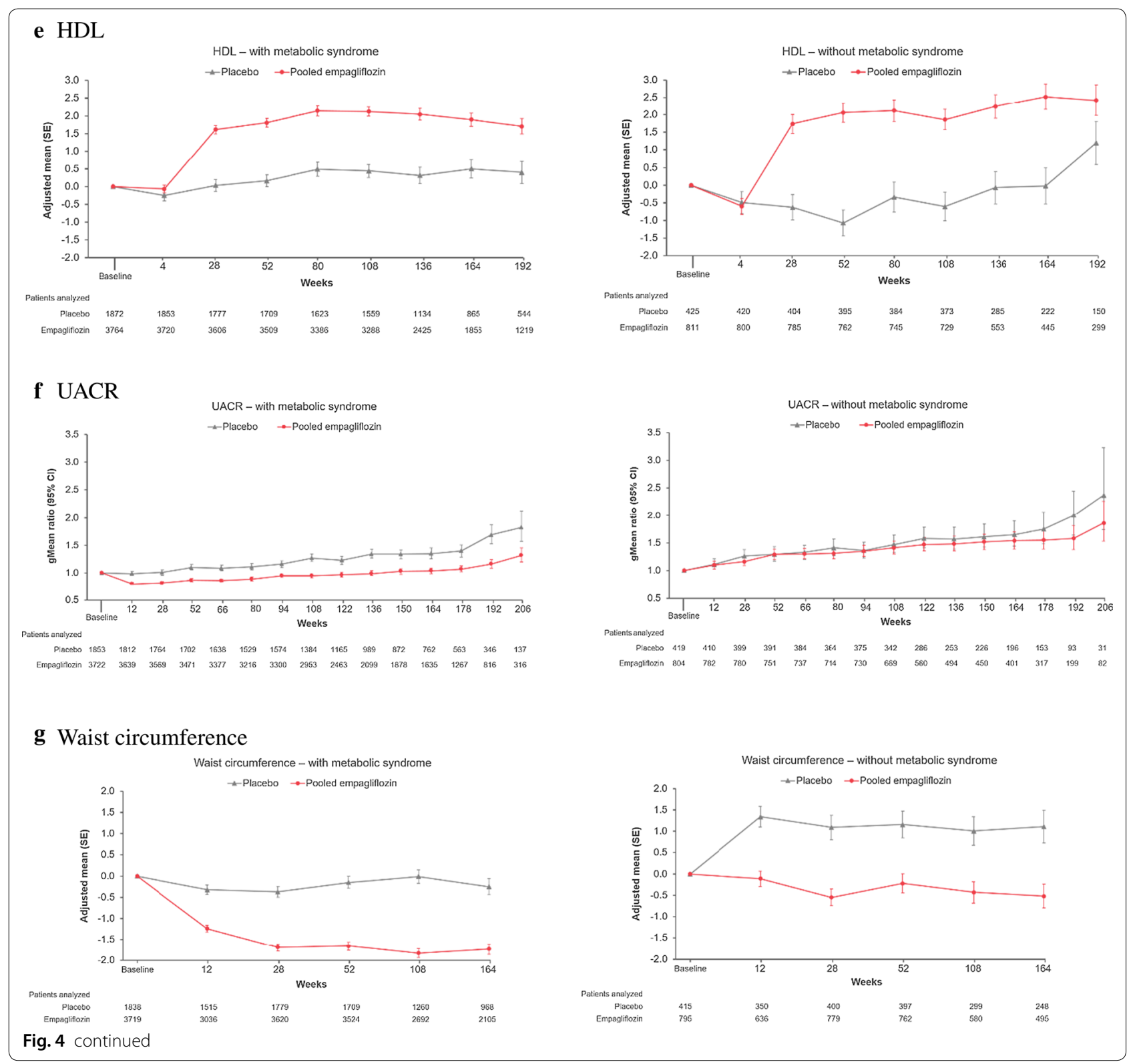

viewed as positive cardiometabolic effects of empagliflozin-some of which could conceivably contribute to the SGLT2 inhibitor's cardiorenal benefits.

Metabolic syndrome is a clustering of interrelated metabolic factors that are associated with increased risk of CV disease and mortality [9]. Insulin resistance/T2D are incorporated in the definition of MetS and, accordingly, patients with T2D have a high prevalence of the MetS. Moreover, patients with T2D have an additive poorer prognosis when multiple components of the MetS are concomitantly present [10-12]. Our study supports that the MetS has prognostic implications in patients with T2D and established ASCVD. In EMPA-REG
OUTCOME, patients with both T2D and MetS had a 1.5- to 3-fold higher incidence of cardiorenal outcomes including $\mathrm{CV}$ mortality. In particular the relative risk of new or worsening nephropathy was high among those with the MetS. This finding is supported by a previous study showing that the MetS was associated with an increased risk of albuminuria progression and worsening of renal function [13]. Moreover, a report from the Dallas Heart Study demonstrated that both the MetS and T2D were independently associated with higher atherosclerotic burden, evaluated by the content of coronary artery calcium and abdominal aortic atherosclerotic plaques [14]. We have also found that the presence of the 
MetS was associated with an increased risk of HF hospitalization. The association of the MetS with HF has been reported in other studies and insulin resistance/T2D likely play a major role in HF progression, supporting our findings [15-19].

The consistent treatment effect of empagliflozin on mortality and cardiorenal and HF outcomes regardless of the MetS status expands previous findings demonstrating consistent $\mathrm{CV}$ benefit across various subgroups. For example, it has been shown that empagliflozin reduced the risk of cardiorenal and mortality outcomes across subgroups based on the TIMI secondary prevention risk score as well as in those with or without HF and presumed resistant hypertension, and heart failure with reduced ejection fraction irrespective of diabetes and chronic kidney disease [5, 20-23]. Findings, that may be generalized to a large proportion of "real-world" patients [24].

The improvement of the individual components of the MetS over time in patients treated with empagliflozin is clinically relevant, as uncontrolled but potentially modifiable MetS risk factors (e.g., blood pressure, HbA1c, cholesterol, and albuminuria) are incrementally associated with adverse outcomes, and patients with T2D with an optimal risk-factor control might have a similar risk of adverse $\mathrm{CV}$ outcomes as people of the same sex and age without T2D [3]. Thus, our findings of an incremental risk in patients with T2D and MetS may increase clinicians' awareness to identify MetS components in their patients. This is important, as, beyond reducing morbidity and mortality, empagliflozin may also improve most of the MetS components (e.g., glycemic control, blood pressure, weight, and albuminuria) and may also reduce left ventricular mass [25].

\section{Limitations}

Our study has some limitations. These are post-hoc data and thus only hypothesis generating. Furthermore, since the population studied in the EMPA-REG OUTCOME trial had ASCVD we do not know if our results might extend to a general, lower risk T2D population. Finally, the large majority of the trial's patients had MetS, limiting the statistical power in any comparisons to the nonMetS group.

\section{Conclusions}

A major proportion of the EMPA-REG OUTCOME population fulfills the criteria for MetS. Those with MetS have increased risk of adverse cardio-renal outcomes. Compared with placebo, empagliflozin improved the individual components of the MetS, as well as mortality and cardio-renal outcomes in patients with and without MetS.

\section{Abbreviations}

ASCVD: Atherosclerotic cardiovascular disease; BMI: Body mass index; BP. Blood pressure; CV: Cardiovascular; eGFR: Estimated glomerular filtration rate; HF: Heart failure; HR: Hazard ratio; MDRD: Modification of Diet in Renal Disease; MetS: Metabolic syndrome; MI: Myocardial infarction; MMRM: Mixed model repeated measurement; T2D: Type 2 diabetes mellitus; UACR: Urinary albumincreatinine ratio; WC: Waist circumference; WHO: World Health Organization; 3P-MACE: 3-point major adverse cardiovascular events.

\section{Acknowledgements}

The authors thank the investigators, coordinators, and patients who participated in this trial. Editorial assistance, limited to the preparation of tables and figures and supported financially by Boehringer Ingelheim, was provided by Paul Lidbury of Elevate Scientific Solutions.

\section{Authors' contributions}

SEI, SV and JPF conceived the idea. APO and JPF drafted the manuscript. SL and IZ provided the statistical expertise. All authors critically reviewed the manuscript, provided feedback the final submitted version. All authors read and approved the final manuscript.

\section{Funding}

The EMPA-REG OUTCOME trial was funded by the Boehringer Ingelheim \& Eli Lilly and Company Diabetes Alliance.

\section{Availability of data and materials}

The sponsor of the EMPA-REG OUTCOME Trial (Boehringer Ingelheim) is committed to responsible sharing of clinical study reports, related clinical documents, and patient level clinical study data. Researchers are invited to submit inquiries via the following website: https://trials.boehringer-ingelheim.com.

\section{Ethics approval and consent to participate}

The trial was conducted in accordance with the principles of the Declaration of Helsinki and the International Conference on Harmonization Good Clinical Practice guidelines and was approved by local authorities. An independent ethics committee or institutional review board approved the clinical protocol at every participating center.

\section{Consent for publication}

All patients provided written informed consent before study entry.

\section{Competing interests}

J.P.F. has received travelling fees from Behringer Ingelheim. S.V. is President of the Canadian Medical and Surgical Knowledge Translation Research Group, a federally incorporated not-for-profit physician organization; holds a Tier 1 Canada Research Chair in Cardiovascular Surgery; S.V. has also received grants and personal fees for speaker honoraria and advisory board participation from AstraZeneca, Bayer, Boehringer Ingelheim, Janssen, and Merck. He has received grants and personal fees for advisory board participation from Amgen, grants from Bristol-Myers Squibb, personal fees for speaker honoraria and advisory board participation from Eli Lilly, Novo Nordisk and Sanofi, and personal fees for speaker honoraria from EOCI Pharmacomm Ltd, Novartis, Sun Pharmaceuticals and Toronto Knowledge Translation Working Group. D.H.F. has received honoraria from Amgen, AstraZeneca, Bl, Eli Lilly and Company, Merck \& Co., and Sanofi. C.W. has received honoraria for consultancy and lecturing from AstraZeneca, Bayer, Bl, GlaxoSmithKline, Eli Lilly and Company, Merck Sharp \& Dome, Mundipharma, Sanofi Genzyme, and Takeda. B.Z. has received research grants awarded to his institution from Bl, AstraZeneca and Novo Nordisk, and honoraria from Janssen, Sanofi, Eli Lilly and Company, BI, Novo Nordisk and Merck Sharp \& Dome. S.E.I. has consulted and/or served on Clinical Trial Steering/Executive/Publications Committees for Boehringer Ingelheim (BI), AstraZeneca, Novo Nordisk, Sanofi/Lexicon Pharmaceuticals, Merck and Abbott. A.P.O, I.Z. and J.T.G. are employees of Boehringer Ingelheim. S.L. has received honoraria for consultancy from BI and F. Hoffmann La Roche. 


\section{Author details}

1 Centre d'Investigations Cliniques Plurithématique Inserm 1433, CHRU de Nancy, Inserm U1116, FCRIN INI- CRCT, Université de Lorraine, Nancy, France. ${ }^{2}$ Division of Cardiac Surgery, St Michael's Hospital, University of Toronto, Toronto, ON, Canada. ${ }^{3}$ Division of Cardiology, St Michael's Hospital, University of Toronto, Toronto, ON, Canada. ${ }^{4}$ Boehringer Ingelheim Norway Ks, Asker, Norway. ${ }^{5}$ Boehringer Ingelheim Pharma GmbH \& Co. KG, Ingelheim, Germany. ${ }^{6}$ Boehringer Ingelheim International $\mathrm{GmbH}$, Ingelheim, Germany. ${ }^{7}$ Würzburg University Clinic, Würzburg, Germany. ${ }^{8}$ Mount Sinai Hospital, Lunenfeld-Tanenbaum Research Institute, University of Toronto, Toronto, ON, Canada. ${ }^{9}$ Yale University School of Medicine, New Haven, CT, USA.

\section{Received: 24 August 2020 Accepted: 15 November 2020}

\section{Published online: 26 November 2020}

\section{References}

1. Tune JD, Goodwill AG, Sassoon DJ, Mather KJ. Cardiovascular consequences of metabolic syndrome. Transl Res. 2017;183:57-70.

2. Alberti KG, Zimmet PZ. Definition, diagnosis and classification of diabetes mellitus and its complications. Part 1: diagnosis and classification of diabetes mellitus provisional report of a WHO consultation. Diabet Med. 1998;15(7):539-53.

3. Rawshani A, Franzen S, Sattar N, Eliasson B, Svensson AM, Zethelius B, Miftaraj M, McGuire DK, Rosengren A, Gudbjornsdottir S. Risk factors, mortality, and cardiovascular outcomes in patients with type 2 diabetes. N Engl J Med. 2018;379(7):633-44.

4. Zinman B, Wanner C, Lachin JM, Fitchett D, Bluhmki E, Hantel S, Mattheus M, Devins T, Johansen OE, Woerle HJ, Broedl UC, Inzucchi SE. Empagliflozin, cardiovascular outcomes, and mortality in type 2 diabetes. N Engl J Med. 2015;373(22):2117-28.

5. Ferreira JP, Fitchett D, Ofstad AP, Kraus BJ, Wanner C, Zwiener I, Zinman B, Lauer S, George JT, Rossignol P, Zannad F. Empagliflozin for patients with presumed resistant hypertension: a post hoc analysis of the EMPA-REG OUTCOME Trial. Am J Hypertens. 2020. https://doi.org/10.1093/ajh/hpaa0 73.

6. Chilton R, Tikkanen I, Cannon CP, Crowe S, Woerle HJ, Broedl UC, Johansen OE. Effects of empagliflozin on blood pressure and markers of arterial stiffness and vascular resistance in patients with type 2 diabetes. Diabetes Obes Metab. 2015;17(12):1180-93.

7. Wanner C, Lachin JM, Inzucchi SE, Fitchett D, Mattheus M, George J, Woerle HJ, Broedl UC, von Eynatten M, Zinman B. Empagliflozin and clinical outcomes in patients with type 2 diabetes mellitus, established cardiovascular disease, and chronic kidney disease. Circulation. 2018;137(2):119-29.

8. Wanner C, Inzucchi SE, Lachin JM, Fitchett D, von Eynatten M, Mattheus M, Johansen OE, Woerle HJ, Broedl UC, Zinman B. Empagliflozin and progression of kidney disease in type 2 diabetes. $\mathrm{N}$ Engl J Med. 2016:375(4):323-34

9. Galassi A, Reynolds K, He J. Metabolic syndrome and risk of cardiovascular disease: a meta-analysis. Am J Med. 2006;119(10):812-9.

10. I padeola A, Adeleye JO. THE metabolic syndrome and accurate cardiovascular risk prediction in persons with type 2 diabetes mellitus. Diabetes Metab Syndr. 2016;10(1):7-12.

11. Song SH, Hardisty CA. Diagnosing metabolic syndrome in type 2 diabetes: does it matter? OJM. 2008;101(6):487-91.

12. Scott $R, O^{\prime}$ Brien $R$, Fulcher G, Pardy C, D'Emden M, Tse D, Taskinen MR, Ehnholm C, Keech A. Effects of fenofibrate treatment on cardiovascular disease risk in 9795 individuals with type 2 diabetes and various components of the metabolic syndrome: the Fenofibrate Intervention and Event Lowering in Diabetes (FIELD) study. Diabetes Care. 2009;32(3):493-8.
13. Chuang SM, Shih HM, Chien MN, Liu SC, Wang CH, Lee CC. Risk factors in metabolic syndrome predict the progression of diabetic nephropathy in patients with type 2 diabetes. Diabetes Res Clin Pract. 2019;153:6-13.

14. Chen K, Lindsey JB, Khera A, De Lemos JA, Ayers CR, Goyal A, Vega GL, Murphy SA, Grundy SM, McGuire DK. Independent associations between metabolic syndrome, diabetes mellitus and atherosclerosis: observations from the Dallas Heart Study. Diab Vasc Dis Res. 2008;5(2):96-101.

15. Li C, Ford ES, McGuire LC, Mokdad AH. Association of metabolic syndrome and insulin resistance with congestive heart failure: findings from the Third National Health and Nutrition Examination Survey. J Epidemiol Community Health. 2007;61(1):67-73.

16. Wang J, Sarnola K, Ruotsalainen S, Moilanen L, Lepisto P, Laakso M, Kuusisto J. The metabolic syndrome predicts incident congestive heart failure: a 20-year follow-up study of elderly Finns. Atherosclerosis. 2010;210(1):237-42.

17. Ingelsson E, Arnlov J, Lind L, Sundstrom J. Metabolic syndrome and risk for heart failure in middle-aged men. Heart. 2006;92(10):1409-13.

18. Adingupu DD, Göpel SO, Grönros J, Behrendt M, Sotak M, Miliotis T, Dahlqvist U, Gan LM, Jönsson-Rylander AC. SGLT2 inhibition with empagliflozin improves coronary microvascular function and cardiac contractility in prediabetic ob/ob(-/-) mice. Cardiovasc Diabetol. 2019;18(1):16.

19. Sun X, Han F, Lu Q, Li X, Ren D, Zhang J, Han Y, Xiang YK, Li J. Empagliflozin ameliorates obesity-related cardiac dysfunction by regulating sestrin2mediated AMPK-mTOR signaling and redox homeostasis in high-fat diet-induced obese mice. Diabetes. 2020;69(6):1292-305.

20. Januzzi J, Ferreira JP, Bohm M, Kaul S, Wanner C, Brueckmann M, Petrie MC, Ofstad AP, Zeller C, George J, Fitchett D, Zannad F. Empagliflozin reduces the risk of a broad spectrum of heart failure outcomes regardless of heart failure status at baseline. Eur J Heart Fail. 2019;21(3):386-8.

21. Fitchett D, Inzucchi SE, Cannon CP, McGuire DK, Scirica BM, Johansen OE, Sambevski S, Kaspers S, Pfarr E, George JT, Zinman B. Empagliflozin reduced mortality and hospitalization for heart failure across the spectrum of cardiovascular risk in the EMPA-REG OUTCOME trial. Circulation. 2019;139(11):1384-95.

22. Park SH, Faroog MA, Gaertner S, Bruckert C, Qureshi AW, Lee HH, Benrahla D, Pollet B, Stephan D, Ohlmann P, Lessinger JM, Mayoux E, Auger C, Morel O, Schini-Kerth VB. Empagliflozin improved systolic blood pressure, endothelial dysfunction and heart remodeling in the metabolic syndrome ZSF1 rat. Cardiovasc Diabetol. 2020;19(1):19.

23. Zannad F, Ferreira JP, Pocock SJ, Zeller C, Anker SD, Butler J, Filippatos G, Hauske SJ, Brueckmann M, Pfarr E, Schnee J, Wanner C, Packer M. Cardiac and kidney benefits of empagliflozin in heart failure across the spectrum of kidney function: insights from the EMPEROR-reduced trial. Circulation. 2020. https://doi.org/10.1161/CIRCULATIONAHA.120.051685.

24. Castellana M, Procino F, Sardone R, Trimboli P, Giannelli G. Generalizability of sodium-glucose co-transporter-2 inhibitors cardiovascular outcome trials to the type 2 diabetes population: a systematic review and metaanalysis. Cardiovasc Diabetol. 2020;19(1):87.

25. Verma S, Mazer CD, Yan AT, Mason T, Garg V, Teoh H, Zuo F, Quan A, Farkouh ME, Fitchett DH, Goodman SG, Goldenberg RM, Al-Omran M, Gilbert RE, Bhatt DL, Leiter LA, Jüni P, Zinman B, Connelly KA. Effect of Empagliflozin on Left Ventricular Mass in Patients With Type 2 Diabetes Mellitus and Coronary Artery Disease: The EMPA-HEART CardioLink-6 Randomized Clinical Trial. Circulation. 2019;140(21):1693-702.

\section{Publisher's Note}

Springer Nature remains neutral with regard to jurisdictional claims in published maps and institutional affiliations.Springer Nature remains neutral with regard to jurisdictional claims in published maps and institutional affiliations. 